\title{
Spirometry Quality in Adults With Very Severe Lung Function Impairment
}

\author{
Luis Torre-Bouscoulet MD MSc, Mónica Velázquez-Uncal MD MSc, \\ Rogelio García-Torrentera MD, Laura Gochicoa-Rangel MD MSc, \\ Rosario Fernández-Plata MSc, Paul Enright MD, and Rogelio Pérez-Padilla MD
}

\begin{abstract}
BACKGROUND: Some technologists worry that patients with very severe lung disease are unable to complete several spirometry maneuvers, which require considerable effort. METHODS: We retrospectively selected all spirometry tests with an $\mathrm{FEV}_{1}<35 \%$ predicted done by adult subjects sent to our pulmonary function laboratory during a 3-y period. We determined the rates and correlates of poor quality test sessions. RESULTS: Approximately $90 \%$ of the tests done by the 558 subjects with very severe lung-function impairment (of $>30,000$ subjects tested during the 3-y period) had adequate quality spirometry. Subjects with airway obstruction were less likely to meet FVC repeatability goals. A poor spirometry quality grade was associated with a very low FVC and a low body mass index, but not older age. CONCLUSIONS: Severe lung disease should not be used as an excuse for not meeting spirometry quality goals. Key words: spirometry; quality control; respiratory impairment; lung function. [Respir Care 2015;60(5):740-743. () 2015 Daedalus Enterprises]
\end{abstract}

\section{Introduction}

The best use of a clinical test, such as spirometry, is obtained if the results are both accurate and reproducible. The most widely accepted goals for the acceptability and repeatability of spirometry tests ${ }^{1}$ were based on the ability of $90 \%$ of out-patients tested by experienced technologists to meet the goals. ${ }^{2}$ Previous reports determined the rates and correlates of good quality spirometry in population-

Drs Torre-Bouscoulet, Velázquez-Uncal, Pérez-Padilla, and GochicoaRangel are affiliated with the Department of Respiratory Physiology, Instituto Nacional de Enfermedades Respiratorias "Ismael Cosío Villegas," Tlalpan; Dr García-Torrentera is affiliated with the Department of Respiratory Therapy, Instituto Nacional de Enfermedades Respiratorias "Ismael Cosío Villegas," Tlalpan; Ms Fernández-Plata is affiliated with the Department of Epidemiology and Social Sciences, Instituto Nacional de Enfermedades Respiratorias "Ismael Cosío Villegas," Tlalpan, México; Dr Enright is retired from the University of Arizona, Tucson, Arizona.

The authors have disclosed no conflicts of interest.

Correspondence: Luis Torre-Bouscoulet MD MSc, Instituto Nacional de Enfermedades Respiratorias "Ismael Cosío Villegas," Colonia, Calzada de Tlalpan 4502, Sección XVI, Delegación Tlalpan, México DF, CP 14080, México. E-mail: luistorreb@gmail.com.

DOI: $10.4187 /$ respcare. 03457 based samples of ambulatory adults, which included very few people with severe pulmonary function impairment $\left(\mathrm{FEV}_{1}<50 \%\right.$ predicted $){ }^{3,4}$ or studied consecutive patients referred to a pulmonary function test (PFT) laboratory, but did not stratify them based on the severity of their impairment. ${ }^{2,5}$ Technologists sometimes state that patients with severe lung function impairment are unable to meet the quality goals, so we retrospectively reviewed the quality of spirometry tests from such subjects tested in our PFT laboratory.

\section{Methods}

Our PFT laboratory serves the largest respiratory institute in Mexico, a tertiary care center with an average of 6,000 out-patients seen per year. For this study, we obtained spirometry results from all adults $(>18 \mathrm{y}$ of age) with a pre-bronchodilator (pre-BD) $\mathrm{FEV}_{1}$ or $\mathrm{FVC}<35 \%$ of predicted ${ }^{6}$ tested for 3 consecutive years $(2008-2010)$. The definition of very severe impairment was according to current interpretation guidelines. ${ }^{7}$ The tests were done by 5 experienced PFT technologists using one of the SensorMedics (Vmax 1022, Yorba Linda, California) instruments in the laboratory. Volume calibration checks were done every morning using a $3.0 \mathrm{~L}$ calibration syringe. 
A single expert (LTB) reviewed copies of the printed reports with the graphs and numeric results of the 3 best FVC maneuvers. He followed the 2005 American Thoracic Society/European Respiratory Society guidelines to determine acceptability and repeatability. ${ }^{1}$ Briefly, a maneuver was considered acceptable if it had a quick start (brisk onset reaching a vertical and narrow peak flow in the flow-volume curve with back extrapolated volume $<0.15 \mathrm{~L}$ or $5 \%$ of $\mathrm{FVC}$ ), lacked artifacts, and had an adequate end-of-test (FET $>6 \mathrm{~s}$ and end of test volume $<25 \mathrm{~mL}$ in the last $1 \mathrm{~s}$ ). Overall test quality grades (A-F) were assigned as done for the Lung Health Study ${ }^{8}$ (see Table 1). We defined adequate quality for interpretation as a test session with 2 acceptable maneuvers with $\mathrm{FEV}_{1}$ and FVC values matching within $200 \mathrm{~mL}$, according to older guidelines. ${ }^{9}$ Poor quality was defined as a test session with a quality grade of D, E, or F. Although we use the lower limit of the normal range for clinical interpretations, for simplicity in this analysis, we categorized tests as having obstruction when the pre-BD $\mathrm{FEV}_{1} / \mathrm{FVC}$ was $<0.70$, and spirometric restriction for the others (because they all had a very low FVC).

The study was approved by the science and bioethics committee of the National Institute of Respiratory Diseases. No specific informed consent for the study was required. Continuous variables are shown as mean $\pm \mathrm{SD}$, whereas the categorical variables are described as frequencies and percentages. To explore potential predictors of poor quality grades (D, E, or F) and suboptimal FVC and $\mathrm{FEV}_{1}$ repeatability, logistic regression models were built, taking into account male gender, age, body mass index, obstruction pattern, FVC $<1 \mathrm{~L}$, and number of maneuvers as independent variables. The level of statistical significance for each test was 2 -tailed $P<.05$. Analysis was performed using a commercial statistics package (Stata, release 12, StataCorp, College Station, Texas).

\section{Results}

From the total of 30,352 spirometry tests done during the 3 -y period, only $558(1.8 \%)$ met the criteria of very

Table 1. Spirometry Quality Grades

\begin{tabular}{|c|c|c|}
\hline Quality Grade & No. of Acceptable Maneuvers & $\Delta \mathrm{FVC}$ and $\Delta \mathrm{FEV}_{1}$ \\
\hline A & 3 & $<150$ \\
\hline B & 3 & $<200$ \\
\hline $\mathrm{C}$ & 2 & $<200$ \\
\hline $\mathrm{D}$ & 2 & $>200$ \\
\hline $\mathrm{E}$ & 1 & NA \\
\hline $\mathrm{F}$ & 0 & NA \\
\hline \multicolumn{3}{|c|}{$\begin{array}{l}\mathrm{FVC}=\text { difference (in milliliters) between the highest and second highest FVC } \\
\Delta \mathrm{FEV} \mathrm{F}_{1}=\text { difference (in milliliters) between the highest and second highest } \mathrm{FEV}_{1} \\
\mathrm{NA}=\text { not applicable }\end{array}$} \\
\hline
\end{tabular}

\section{QUICK LOOK}

\section{Current knowledge}

The most widely accepted goals for the acceptability and repeatability of spirometry tests are based on the ability of $90 \%$ of out-patients tested by experienced technologists to meet the stated goals. To date, these criteria have not been well studied in subjects with severe pulmonary impairment $\left(\mathrm{FEV}_{1}<50 \%\right.$ of predicted). In this group, experienced pulmonary function technicians often report problems meeting repeatability standards.

\section{What this paper contributes to our knowledge}

This study demonstrates that experienced technologists working in a pulmonary function laboratory can meet spirometry quality goals in $90 \%$ of patients who have severe lung function impairment. The presence of severe lung disease should not negatively affect spirometry quality goals.

low lung function from an adult for inclusion in this study (Table 2). Due to the selection criteria, the mean $\mathrm{FEV}_{1}$ was only $28 \%$ of predicted. Adequate quality spirometry (quality grade A, B, or C) was obtained for $89.6 \%$ of the pre-BD test. The quality was slightly better post-BD (91.8\%) in the 414 subjects who performed post-BD spirometry. Subjects with spirometric restriction had slightly more difficulty obtaining good quality $(189 / 210,88.6 \%)$ when compared with subjects with airway obstruction $(311 / 348$, 90.2\%). The 198 subjects with a very low FVC (below $1.0 \mathrm{~L})$ were less likely than the other subjects to have acceptable quality $(85.4 \%$ vs $92.0 \%, P=.02)$.

Subjects with obstruction were less likely to meet FVC repeatability goals when compared with subjects with restriction, but did not have trouble meeting $\mathrm{FEV}_{1}$ repeatability goals (see Table 3 ). Subjects with a very low FVC (below $1 \mathrm{~L}$ ) more easily met FVC repeatability goals when compared with the other subjects with low lung function (see Table 4). When the $\mathrm{FEV}_{1}$ or FVC repeatability goals were not achieved, the technologist was approximately $36 \%$ more likely to have obtained additional maneuvers.

A poor spirometry quality grade was associated with a very low FVC and a low body mass index (see Table 5). Men, subjects who were malnourished (lower body mass index), and those with a pattern of obstruction were less likely to have obtained optimal FVC repeatability. Older adults with very low lung function were no more likely than younger ones to have a poor spirometry quality grade. 
Table 2. General Characteristics of the 558 Prebronchodilator Spirometry Tests

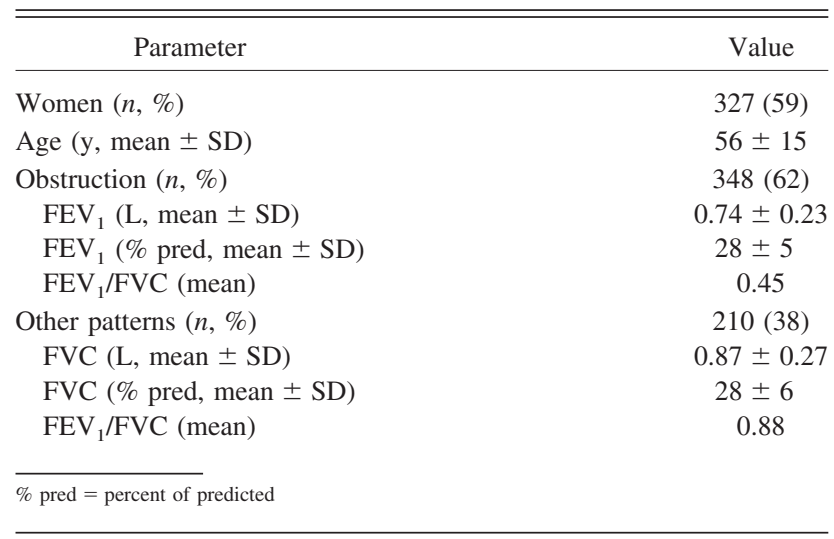

Table 3. Prebronchodilator FVC and $\mathrm{FEV}_{1}$ Repeatability Stratified by Pattern

\begin{tabular}{lccc}
\hline \hline \multicolumn{1}{c}{ Repeatability } & Obstruction & Restriction & All \\
\hline FVC (mL) & & & \\
$\quad$ 50th percentile & 40 & 30 & 40 \\
$\quad$ 90th percentile & 140 & 90 & 120 \\
FEV $_{1}(\mathrm{~mL})$ & & & \\
$\quad$ 50th percentile & 20 & 30 & 30 \\
90th percentile & 80 & 80 & 80 \\
$\Delta \mathrm{FVC}<100 \mathrm{~mL} \mathrm{(n, \% )}$ & $257(77.8)$ & $172(91)^{*}$ & $429(82.6)$ \\
$\Delta \mathrm{FVC}<150 \mathrm{~mL}(n, \%)$ & $302(91.5)$ & $187(98.9)^{*}$ & $489(94.2)$ \\
$\Delta \mathrm{FEV}_{1}<100 \mathrm{~mL}(n, \%)$ & $306(92.7)$ & $180(95.2)$ & $486(93.6)$ \\
$\Delta \mathrm{FEV}_{1}<150 \mathrm{~mL}(n, \%)$ & $326(98.7)$ & $186(98.4)$ & $512(98.6)$
\end{tabular}

Comparisons were not significant $(P>.05)$ unless otherwise indicated by footnote.

$* P<.001$ obstruction vs restriction.

$\Delta \mathrm{FVC}=$ difference (in milliliters) between the highest and second highest FVC

$\Delta \mathrm{FEV}_{1}=$ difference (in milliliters) between the highest and second highest $\mathrm{FEV}_{1}$

\section{Discussion}

Our PFT technologists were able to meet or exceed current quality goals for spirometry tests for $90 \%$ of adults with very severe lung-function impairment. Thus, severe lung disease should not be used as an excuse for not meeting spirometry quality goals. When acceptable quality is not obtained after performing 8 maneuvers, some subjects will meet the quality goals after inhaling a bronchodilator. A very low FVC (severe restriction) is associated with slightly lower average quality of tests; however, the within-test-session repeatability of FVC is excellent in this group, which improves the confidence in changes in FVC seen from visit to visit.

It is not surprising that malnourished subjects with a low body mass index were less likely to be able to repeatably take deep inhalations and thus obtain highly repeatable FVCs. Subjects with very severe air-flow limitation

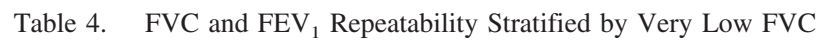
$(<1.0 \mathrm{~L}, n=171)$ and $\mathrm{FVC} \geq 1 \mathrm{~L}(n=348)$

\begin{tabular}{|c|c|c|}
\hline Repeatability & $\mathrm{FVC}<1.0 \mathrm{~L}$ & $\mathrm{FVC} \geq 1 \mathrm{~L}$ \\
\hline \multicolumn{3}{|l|}{$\mathrm{FVC}(\mathrm{mL})$} \\
\hline 50th percentile & 30 & 40 \\
\hline 90th percentile & 90 & 130 \\
\hline \multicolumn{3}{|l|}{$\mathrm{FEV}_{1}$} \\
\hline 50th percentile & 20 & 30 \\
\hline 90th percentile & 80 & 80 \\
\hline$\Delta \mathrm{FVC}<100 \mathrm{~mL}(n, \%)$ & $156(91.2)$ & $273(78.4)^{*}$ \\
\hline$\Delta \mathrm{FVC}<150 \mathrm{~mL}(n, \%)$ & $170(99.4)$ & $319(91.6) *$ \\
\hline$\Delta \mathrm{FEV}_{1}<100 \mathrm{~mL}(n, \%)$ & $163(95.3)$ & $323(92.8)$ \\
\hline$\Delta \mathrm{FEV}_{1}<150 \mathrm{~mL}(n, \%)$ & $169(98.8)$ & $343(98.5)$ \\
\hline \multicolumn{3}{|c|}{ 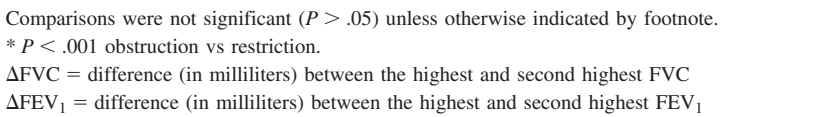 } \\
\hline
\end{tabular}

and accompanying air trapping were also less likely to have highly repeatable FVCs. This is likely to be the result of differences in forced expiratory time (even when they were urged to continue to exhale more than $6 \mathrm{~s}$ ). The use of $\mathrm{FEV}_{6}$ as a surrogate for FVC in such subjects increases the repeatability of the estimate of vital capacity. ${ }^{10}$ The inspiratory capacity (which depends on maximal inhalation but not maximal exhalation) is probably a better index of the degree of air trapping in subjects with very severe airway obstruction. The $\mathrm{FEV}_{6}$ (and probably the inspiratory capacity) are more repeatable and reproducible from visit to visit when compared with the FVC. ${ }^{11,12}$

The study by Borg and colleagues 5 published in RESPIRATORY CARE provided an excellent comparison of studies that reported the rates of meeting ATS spirometry goals. Study sites have included primary care, ${ }^{13,14}$ clinical trials, ${ }^{3,15,16}$ and PFT laboratories. ${ }^{5,12}$ Rates of good quality spirometry varied from 40 to $90 \%$, and seem to depend more on technologist dedication, incentives, and disincentives than the initial training of the technologists or the characteristics of the subjects.

Limitations of our study include the following: (1) our results may not apply to other sites or to children; (2) our technologists had considerable training, experience, and motivation, so these results may not be achieved by less experienced technologists; (3) we did not review the quality of tests of diffusing capacity, body plethysmography, or forced oscillation, which may be easier to perform; (4) we did not have enough subjects with repeat tests done several weeks later, so we could not evaluate the effect of learning; (5) we did not measure the cognitive level and educational level of the subjects, factors that have previously been shown to be correlated with the ability to perform good quality spirometry; and (6) the spirometers we used provided quality feedback messages and the flow- 
Table 5. Predictors of Poor Quality Grades (D, E, or F) and Suboptimal FVC and FEV 1 Repeatability (Univariate Analyses)

\begin{tabular}{|c|c|c|c|c|c|c|}
\hline & \multicolumn{2}{|c|}{ Poor Quality Grade } & \multicolumn{2}{|c|}{$\Delta \mathrm{FVC}>100 \mathrm{~mL}$} & \multicolumn{2}{|c|}{$\Delta \mathrm{FEV}_{1}>100 \mathrm{~mL}$} \\
\hline & $\begin{array}{l}\text { Odds Ratio } \\
(95 \% \text { CI })\end{array}$ & $P$ & $\begin{array}{l}\text { Odds ratio } \\
(95 \% \text { CI })\end{array}$ & $P$ & $\begin{array}{l}\text { Odds Ratio } \\
(95 \% \mathrm{CI})\end{array}$ & $P$ \\
\hline Male & $\begin{array}{c}0.92 \\
(0.52-1.60)\end{array}$ & .77 & $\begin{array}{c}2.35 \\
(1.47-3.74)\end{array}$ & $<.001$ & $\begin{array}{c}1.46 \\
(0.72-2.97)\end{array}$ & .28 \\
\hline Age & $\begin{array}{c}1.0 \\
(0.98-1.02)\end{array}$ & .46 & $\begin{array}{c}1.01 \\
(0.99-1.02)\end{array}$ & .16 & $\begin{array}{c}1.00 \\
(0.98-1.03)\end{array}$ & .57 \\
\hline BMI & $\begin{array}{c}0.93 \\
(0.89-0.99)\end{array}$ & .02 & $\begin{array}{c}0.98 \\
(0.94-1.02)\end{array}$ & .53 & $\begin{array}{c}0.97 \\
(0.91-1.03)\end{array}$ & .42 \\
\hline Obstruction & $\begin{array}{c}0.83 \\
(0.48-1.45)\end{array}$ & .53 & $\begin{array}{c}2.87 \\
(1.63-5.04)\end{array}$ & $<.001$ & $\begin{array}{c}1.56 \\
(0.71-3.44)\end{array}$ & .26 \\
\hline $\mathrm{FVC}<1 \mathrm{~L}$ & $\begin{array}{c}1.95 \\
(1.13-3.38)\end{array}$ & .01 & $\begin{array}{c}0.35 \\
(0.19-0.63)\end{array}$ & $<.001$ & $\begin{array}{c}0.63 \\
(0.27-1.43)\end{array}$ & .27 \\
\hline No. of maneuvers & $\begin{array}{c}0.85 \\
(0.64-1.13)\end{array}$ & .28 & $\begin{array}{c}1.36 \\
(1.11-1.67)\end{array}$ & .003 & $\begin{array}{c}1.32 \\
(0.98-1.79)\end{array}$ & .06 \\
\hline \multicolumn{7}{|c|}{$\begin{array}{l}\mathrm{FVC}=\text { difference (in milliliters) between the highest and second highest FVC } \\
\Delta \mathrm{FEV} \mathrm{F}_{1}=\text { difference (in milliliters) between the highest and second highest } \mathrm{FEV}_{1} \\
\mathrm{BMI}=\text { body mass index }\end{array}$} \\
\hline
\end{tabular}

volume and volume-time curves were superimposed, so our technologists knew when additional maneuvers were needed to meet quality goals.

\section{Conclusions}

Our study demonstrates that experienced technologists working in a PFT laboratory can meet spirometry quality goals in 9 of every 10 patients who have severe lungfunction impairment. Therefore, severe lung disease should not be used as an excuse for not meeting spirometry quality goals.

\section{REFERENCES}

1. Miller MR, Hankinson J, Brusasco V, Burgos F, Casaburi R, Coates A, et al. Standardisation of spirometry. Eur Respir J 2005;26(2):319338.

2. Enright PL, Beck KC, Sherrill DL. Repeatability of spirometry in 18,000 adult patients. Am J Respir Crit Care Med 2004;169(2):235238.

3. Enright P, Vollmer WM, Lamprecht B, Jensen R, Jithoo A, Tan W, et al. Quality of spirometry tests performed by 9893 adults in 14 countries: the BOLD study. Respir Med 2011;105(10):1507-1515.

4. Tan WC, Bourbeau J, O'Donnell D, Aaron S, Maltais F, Marciniuk D, et al. Quality assurance of spirometry in a population-based study -predictors of good outcome in spirometry testing. COPD 2014; 11(2):143-151.

5. Borg BM, Hartley MF, Bailey MJ, Thompson BR. Adherence to acceptability and repeatability criteria for spirometry in complex lung function laboratories. Respir Care 2012;57(12):2032-2038.

6. Pérez-Padilla R, Valdivia G, Muiño A, López MV, Márquez MN, Montes de Oca M, et al. Spirometric reference values in 5 large Latin American cities for subjects aged 40 years or over. Arch Bronconeumol 2006;42(7):317-325.
7. Pellegrino R, Viegi G, Brusasco V, Crapo RO, Burgos F, Casaburi $\mathrm{R}$, et al. Interpretative strategies for lung function tests. Eur Respir J 2005;26(5):948-968.

8. Enright PL, Johnson LR, Connett JE, Voelker H, Buist AS. Spirometry in the Lung Health Study. 1. Methods and quality control. Am Rev Respir Dis 1991;143(6):1215-1223.

9. Hankinson JL, Bang KM. Acceptability and reproducibility criteria of the American Thoracic Society as observed in a sample of the general population. Am Rev Respir Dis 1991;143(3):516-521.

10. Kainu A, Lindqvist A, Sarna S, Lundbäck B, Sovijärvi A. Responses of FEV6, FVC, and FET to inhaled bronchodilator in the adult general population. Respir Res 2009;10:71. doi: 10.1186/1465-9921-1071.

11. Pérez-Padilla R, Wehrmeister FC, Celli BR, Lopez-Varela MV, Montes de Oca M, Muiño A, et al. Reliability of the FEV1/FEV6 to diagnose airflow obstruction compared with the FEV1/FVC: the PLATINO longitudinal study. PLoS One 2013;8(8):e67960. doi: 10.1371/journal.pone.0067960.

12. Swanney MP, Jensen RL, Crichton DA, Beckert LE, Cardno L, Crapo RO. FEV6 is an acceptable surrogate for FVC in the spirometric diagnosis of airway obstruction and restriction. Am J Respir Crit Care Med 2000;162(3 Pt 1):917-919.

13. Leuppi JD, Miedinger D, Chhajed PN, Buess C, Schafroth, S, Bucher HC, Tamm M. Quality of spirometry in primary care for case finding of airway obstruction in smokers. Respiration 2010;79(6):469-474.

14. Licskai CJ, Sands TW, Paolatto L, Nicoletti I, Ferrone M. Spirometry in primary care: an analysis of spirometery test quality in a regional primary care asthma program. Can Respir J 2012;19(4):249254.

15. Malmstrom K, Peszek I, Botto A, Lu S, Enright PL, Reiss TF. Centralized spirometry quality control improves efficiency of asthma clinical trials. Controlled Clin Trials 2002;23(2):143-156.

16. Enright PL, Skloot GS, Cox-Ganser JM, Udasin IG, Herbert R. Quality of spirometry performed by 13,599 participants in the World Trade Center Worker and Volunteer Medical Screening Program. Respir Care 2010;55(3):303-309. 